\title{
AVALIAÇÃO NUTRICIONAL DO BAGAÇO DE CANA-DE-AÇÚCAR ENRIQUECIDO COM VINHAÇA EM DIETAS PARA COELHOS EM CRESCIMENTO ${ }^{1}$
}

\author{
FELIPE NORBERTO ALVES FERREIRA ${ }^{2 *}$, WALTER MOTTA FERREIRA ${ }^{3}$, KATIUSCIA CRISTINA DAS NEVES \\ MOTA $^{4}$, CLARICE SPERIDIÃO SILVA NETA ${ }^{5}$, LEONARDO BOSCOLI LARA ${ }^{6}$, ESTÁCIO ALVES DOS SANTOS ${ }^{7}$
}

RESUMO - Objetivando-se avaliar a utilização digestiva e o desempenho de coelhos em crescimento alimentados com dietas contendo bagaço de cana enriquecido com vinhaça foram utilizados 118 coelhos da raça Nova Zelândia branco para ensaios de digestibilidade, cecotrofia e desempenho. O delineamento foi o inteiramente casualizado, sendo aplicados nos ensaios de digestibilidade e cecotrofia três tratamentos (uma dieta referência, uma dieta contendo bagaço de cana e uma dieta contendo bagaço de cana enriquecido com vinhaça) e no desempenho quatro tratamentos $\left(0,50,100\right.$ e $150 \mathrm{~g} \mathrm{~kg}^{-1}$ de bagaço de cana enriquecido com vinhaça). Os dados foram submetidos à análise de variância e posteriormente realizadas comparações entre as médias dos tratamentos. O bagaço de cana enriquecido ou não com vinhaça altera o consumo, excreção e os coeficientes de digestibilidade da matéria seca, matéria mineral, matéria orgânica, proteína bruta, extrato etéreo e energia bruta. A inclusão de vinhaça promove a melhoria dos valores de energia e proteína digestível do bagaço de cana. Houve alteração na matéria seca dos cecotrofos, enquanto que não houve na proteína bruta dos cecotrofos pela inclusão do bagaço de cana enriquecido ou não com vinhaça. Houve redução da contribuição nutritiva em matéria seca, a partir da inclusão dos alimentos teste. Esta inclusão não afetou contribuição nutritiva em proteína bruta. A utilização do bagaço de cana enriquecido com vinhaça em dietas para coelhos em crescimento se mostrou viável, de modo que a inclusão não alterou o ganho de peso diário dos animais e, portanto, o tempo necessário para atingir o peso de abate.

Palavras-chave: Alimentação. Cecotrofia. Fibra. Produtividade. Resíduo.

\section{NUTRITIONAL EVALUATION OF SUGARCANE BAGASSE ENRICHED WITH VINASSE IN DIETS FOR GROWING RABBITS}

\begin{abstract}
Aiming to evaluate the digestive use and performance of growing rabbits fed with diets containing sugarcane bagasse enriched with vinasse, 118 New Zealand white rabbits was used in a digestibility, caecotrophy and performance trials. The experimental design was completely randomized, being applied in the digestibility and caecotrophy three treatments (a reference diet, a diet containing sugarcane bagasse and a diet containing sugarcane bagasse enriched with vinasse) and in performance trial, four treatments $(0,50,100$ and $150 \mathrm{~g} \mathrm{~kg}^{-1}$ of bagasse enriched with vinasse). The data were subjected to variance analysis and subsequently carried out comparisons between the averages of the treatments. The bagasse enriched or not with vinasse changes consumption, excretion and the digestibility coefficients of dry matter, mineral matter, organic matter, crude protein, ether extract and gross energy. The inclusion of vinasse promotes the improvement of the values of digestible energy and digestible protein of bagasse. There was no change in the dry matter of the cecotrophes, while there wasn't on the crude protein of cecotrophes by the inclusion of the bagasse enriched or not with vinasse. There was a reduction of the nutritional contribution in dry matter, from the inclusion of test feeds. This did not affect nutritional contribution in crude protein. The use of bagasse enriched with vinasse in diets for growing rabbits proved viable, so that the inclusion did not alter the average daily weight gain of animals and therefore, the time required to reach slaughter weight.
\end{abstract}

Keywords: Feeding, Caecotrophy, Fiber, Productivity, Waste.

\footnotetext{
*Autor para correspondência.

${ }^{1}$ Recebido para publicação em 22/04/2014; aceito em 30/07/2015.

Parte da Dissertação de Mestrado do primeiro autor apresentada à UFMG.

${ }^{2}$ Doutorando em Zootecnia, Departamento de Zootecnia da Escola de Veterinária, UFMG, Caixa postal 567, 30123-970, Belo Horizonte (MG), Brasil; felipe.norberto@yahoo.com.br.

${ }^{3}$ Professor titular, Departamento de Zootecnia da Escola de Veterinária, UFMG, Caixa postal 567, 30123-970, Belo Horizonte (MG), Brasil; waltermf@ufmg.br.

${ }^{4}$ Mestranda em Zootecnia, Departamento de Zootecnia da Escola de Veterinária, UFMG, Caixa postal 567, 30123-970, Belo Horizonte (MG), Brasil; katiusciazootecnia@hotmail.com.

${ }^{5}$ Doutoranda em Zootecnia, Departamento de Zootecnia da Escola de Veterinária, UFMG, Caixa postal 567, 30123-970, Belo Horizonte (MG), Brasil; clarice.zootecnia@yahoo.com.br.

${ }^{6}$ Professor Adjunto, Departamento de Zootecnia da Escola de Veterinária, UFMG, Caixa postal 567, 30123-970, Belo Horizonte (MG), Brasil; leoboscoli@gmail.com.

${ }^{7}$ Professor Adjunto, Departamento Zootecnia da Universidade Estadual do Piauí, UESPI, CEP 64.980-000. Corrente (PI), Brasil; estacioalvess@hotmail.com.
} 


\section{INTRODUÇ̃̃̃O}

O interesse na adição de subprodutos da agroindústria de biocombustíveis em dietas para coelhos está focado na busca de ingredientes não competitíveis com a alimentação humana, que promovam desempenho produtivo e rentabilidade satisfatórios, somando-se ao fato de possibilitar maiores opções de destino de resíduos potencialmente poluidores ao ambiente.

A agroindústria de cana-de-açúcar é uma das fontes de maior impacto na contaminação do lençol freático nos países onde estas indústrias operam (STRAPASSON, 2006), devido ao descarte desregrado de vinhaça nas regiões próximas a ela. Dentre os usos da vinhaça, objetivando-se um melhor destino a esse resíduo, está a sua incorporação em dietas (OLIVEIRA et al., 2013) ou o enriquecimento de fontes fibrosas através de seu encharque em vinhaça (COELHO, 2010).

Quando comparado a outras espécies nãoruminantes o sistema digestivo dos coelhos é caracterizado pela presença de um ceco funcional e sua importância na degradação da fibra. Este órgão contribui com até $40 \%$ do peso total do trato gastrointestinal e abriga uma abundante, diversa e ativa comunidade microbiana (MONTEILS et al. 2008).

A interação complexa entre os microrganismos torna esse órgão uma peça chave na fisiologia digestiva do coelho tanto como o maior sítio de fermentação de componentes alimentares como também para a reciclagem de proteína microbiana através da cecotrofia (VILLAMIDE et al., 2010).

$O$ bagaço de cana como fonte de fibra para coelhos em crescimento, apesar de seu baixo valor nutricional, quando utilizada em dietas corretamente balanceadas pode ser uma alternativa na alimentação destes animais, principalmente em regiões sucroalcooleiras (ZANATO, 2008). Hidalgo et al. (2009) afirmam que a vinhaça tem sido utilizada na forma líquida como aditivo na alimentação animal, uma vez que esta apresenta propriedades probióticas e palatabilizantes. Sua utilização como aditivo contribui favoravelmente a resultados satisfatórios sobre a conversão alimentar, ganho de peso e aumento do peso corporal, devido a presença de ácidos orgânicos que melhoram a digestão e a utilização dos nutrientes, além do envolvimento na síntese de vitaminas e absorção mineral.

$\mathrm{O}$ enriquecimento de ingredientes fibrosos a partir da vinhaça segue o mesmo princípio de maximização na utilização de subprodutos da agroindústria, sobretudo por se tratar de um efluente altamente poluente, abundante no Brasil e de difícil disposição final, razão pela qual seu uso contribui de forma significativa para a preservação ambiental.

O objetivo com este trabalho foi avaliar nutricionalmente dietas a base de bagaço de cana-deaçúcar enriquecido com vinhaça para coelhos em crescimento e seus efeitos sobre a composição química, contribuição nutritiva dos cecotrofos e desempenho.

\section{MATERIAL E MÉTODOS}

\section{Ensaio de digestibilidade}

O ensaio de digestibilidade foi conduzido no Laboratório de Metabolismo e Nutrição Animal situado nas dependências do Departamento de Zootecnia da Escola de Veterinária da Universidade Federal de Minas Gerais durante os meses de maio e junho de 2013, com o intuito de se obter os coeficientes de digestibilidade da matéria seca e dos nutrientes e as concentrações de energia digestível (ED) e proteína digestível (PD) das dietas experimentais. A condução se deu in vivo, com a utilização de 30 coelhos da raça Nova Zelândia branco (10 animais de ambos os sexos por dieta), com 55 dias de idade, em um delineamento inteiramente casualizado. Três dietas foram formuladas (Tabela 1), sendo uma referência (REF), formulada a fim de atender as exigências nutricionais estabelecidas por De Blas e Mateos (2010), e outras duas geradas a partir da substituição de $300 \mathrm{~g} \mathrm{~kg}^{-1}$ dos macro ingredientes (alimentos excetuando-se um núcleo composto por melaço em pó, sal, premix, DL-metionina e L-lisina) por bagaço de cana (BC) e bagaço de cana enriquecido com vinhaça (BCV). Para obtenção dos coefícientes de digestibilidade aparente dos princípios nutritivos das dietas utilizou-se a equação sugerida por Schneider e Flatt (1975). Os cálculos para estimativa da ED e PD dos alimentos teste foram efetuados segundo Villamide (1995).

Na Tabela 2 está contida a composição analisada dos alimentos e dietas. Os animais foram mantidos em gaiolas equipadas com telas para coleta das fezes, de acordo com o método europeu padrão (PÉREZ et al., 1995). Foi realizado um período de adaptação às dietas e gaiolas de sete dias seguidos por quatro dias de colheita, nos quais houve consumo ad libitum. Durante o período experimental foi mantido o fotoperíodo natural e a temperatura média do ambiente, obtida por meio de termômetro de máxima e mínima analógico, diariamente às $16 \mathrm{~h}$, com 
F. N. A. FERREIRA et al.

Tabela 1. Composição das dietas experimentais dos ensaios de digestibilidade e cecotrofia

\begin{tabular}{lccc}
\hline & Ingredientes & \multicolumn{3}{c}{ Dietas $\left(\mathrm{g} \mathrm{kg}^{-1}\right)$} \\
\cline { 2 - 4 } & $\mathrm{REF}$ & $\mathrm{BC}$ & $\mathrm{BCV}$ \\
\hline Bagaço de cana-de-açúcar & - & 289,3 & - \\
Bagaço + Vinhaça & - & - & 289,3 \\
Feno de alfafa & 349,1 & 244,4 & 244,4 \\
Farelo de trigo & 201,7 & 141,2 & 141,2 \\
Farelo de soja & 130,1 & 91,1 & 91,1 \\
MDPS & 150,0 & 105,0 & 105,0 \\
Milho & 100,0 & 70,0 & 70,0 \\
Óleo de soja & 20,0 & 14,0 & 14,0 \\
Fosfato bicálcico & 7,9 & 5,5 & 5,5 \\
Calcário & 5,4 & 3,8 & 3,8 \\
Melaço de cana em pó & 20,0 & 20,0 & 20,0 \\
Sal comum & 5,0 & 5,0 & 5,0 \\
Premix & 5,0 & 5,0 & 5,0 \\
DL-Metionina & 2,34 & 2,34 & 2,34 \\
L-Lisina & 3,46 & 3,46 & 3,46 \\
\hline
\end{tabular}

REF - dieta referência;

$\mathrm{BC}$ - dieta referência substituída em $300 \mathrm{~g} \mathrm{~kg}^{-1}$ por bagaço de cana-de-açúcar;

$\mathrm{BCV}$ - dieta referência substituída em $300 \mathrm{~g} \mathrm{~kg}^{-1}$ por bagaço de cana-de-açúcar enriquecido com vinhaça;

Bagaço + Vinhaça - bagaço de cana-de-açúcar enriquecido com $20 \%(\mathrm{~m} / \mathrm{m})$ de vinhaça;

MDPS - Milho desintegrado com palha e sabugo;

${ }^{1}$ Composição do Premix por kg do produto: Vit. A, 2000000 UI; Vit. D3, 20000UI; Vit. E, 4000mg; Vit. K3, 722mg; Vit. B1, 400mg; Vit. B2, 1000mg; Vit. B6, 600mg; Vit. B12, 2000mcg; Niacina, 6000mg; Ácido fólico, 100mg; Ácido pantotênico, 3000mg; Biotina, 21mg; Cloreto de Colina, 100000mg; Selênio, 19mg; Iodo, 140mg; Cobalto, 200mg; Iron, 20000mg; Cobre, 4000mg; Manganês, 4000mg, Zinco, 14000mg.

Tabela 2. Composição nutricional analisada das dietas experimentais e dos ingredientes teste

\begin{tabular}{|c|c|c|c|c|c|}
\hline Composição nutricional $\left(\mathrm{g} \mathrm{kg}^{-1}\right)$ & Bagaço de cana & Bagaço + Vinhaça & REF & $\mathrm{BC}$ & $\mathrm{BCV}$ \\
\hline Matéria seca & 908,1 & 835,1 & 911,0 & 896,6 & 890,0 \\
\hline Proteína bruta & 20,8 & 22,6 & 177,4 & 141,5 & 149,6 \\
\hline Matéria orgânica & 988,7 & 988,5 & 916,3 & 925,2 & 932,2 \\
\hline Matéria mineral & 11,3 & 11,5 & 83,7 & 74,8 & 67,8 \\
\hline Fibra em detergente neutro & 793,9 & 759,4 & 339,9 & 476,8 & 522,9 \\
\hline Fibra em detergente ácido & 509,0 & 535,4 & 165,7 & 233,5 & 269,4 \\
\hline Ligninas & 100,6 & 72,1 & 37,4 & 43,5 & 40,2 \\
\hline Hemiceluloses $^{1}$ & 284,9 & 224 & 174,2 & 243,3 & 253,5 \\
\hline Celulose $^{2}$ & 408,4 & 463,3 & 128,3 & 190 & 229,2 \\
\hline Extrato etéreo & 8,1 & 7,70 & 63,2 & 43,5 & 42,3 \\
\hline Cálcio & 8,4 & 8,3 & 14,0 & 14,2 & 13,6 \\
\hline Fósforo total & 11,9 & 12,5 & 9,6 & 13,8 & 15,4 \\
\hline Energia bruta $\left(\mathrm{Kcal} \mathrm{kg}^{-1}\right)$ & 4466,02 & 4875,21 & 4520,74 & 4463,18 & 4514,01 \\
\hline \multicolumn{6}{|l|}{ Valores nutricionais $^{3}$} \\
\hline $\mathrm{PD}, \mathrm{g} \mathrm{kg}^{-1}$ & 2,04 & 3,27 & 127,3 & 94,4 & 98,4 \\
\hline $\mathrm{ED}, \mathrm{Kcal} \mathrm{kg}^{-1}$ & 351,56 & 555,81 & 2780,25 & 2037,66 & 2112,19 \\
\hline REL ED/PD, $\mathrm{g} \mathrm{Kcal}^{-1}$ & - & - & 21,84 & 21,58 & 21,46 \\
\hline
\end{tabular}

Bagaço + Vinhaça - bagaço de cana-de-açúcar enriquecido com $20 \%$ (m/m) de vinhaça;

$\mathrm{REF}$ - dieta referência;

$\mathrm{BC}$ - dieta referência substituída em $300 \mathrm{~g} \mathrm{~kg}^{-1}$ por bagaço de cana-de-açúcar;

$\mathrm{BCV}$ - dieta referência substituída em $300 \mathrm{~g} \mathrm{~kg}^{-1}$ por bagaço de cana-de-açúcar enriquecido com vinhaça;

${ }^{1}$ FDN-FDA;

${ }^{2}$ FDA-Ligninas;

${ }^{3}$ Dados obtidos segundo cálculos de Villamide (1995), de acordo com os resultados do ensaio de digestibilidade;

PD - proteína digestível

ED - energia digestível;

REL ED/PD - relação entre energia digestível e proteína digestível. 


\section{Ensaio de cecotrofia}

Ao final do ensaio de digestibilidade foi realizado o ensaio de cecotrofia, sendo utilizado os mesmos 30 coelhos quando estes atingiram 66 dias de idade. Nesse ensaio foram empregados colares circulares de madeira para contenção que impedissem o consumo dos cecotrofos. A coleta destes foi realizada a cada duas horas por um período de 24 horas ininterruptas. Após a colheita os cecotrofos foram pesados e congelados para posteriores análises. A temperatura encontrada no ambiente experimental foi com a máxima de $22,4{ }^{\circ} \mathrm{C}$ e mínima de $16,7^{\circ} \mathrm{C}$. As dietas experimentais utilizadas foram as mesmas do experimento de digestibilidade (Tabela 1 e 2). Para obtenção dos valores de contribuição nutritiva dos cecotrofos utilizou-se a fórmula sugerida por Carabaño (1989).

\section{Ensaio de desempenho produtivo}

O ensaio de desempenho foi conduzido no setor de cunicultura da Fazenda Experimental Prof. Hélio Barbosa da Escola de Veterinária da Universidade Federal de Minas Gerais, visando mensurar o desempenho dos animais do desmame até atingirem peso vivo médio de $2 \mathrm{~kg}$. Um total de 88 coelhos da raça Nova Zelândia branco de ambos os sexos, des- mamados aos $30 \pm 1$ dias, foram distribuídos em quatro tratamentos em um delineamento inteiramente casualizado, apresentando peso vivo à desmama de $729,03 \pm 98,12 \mathrm{~g}$. Os animais foram alojados individualmente em gaiolas e alimentados diariamente no início da manhã e no final da tarde. Ração e água foram oferecidos ad libitum. $\mathrm{O}$ experimento foi conduzido nos meses de novembro e dezembro de 2013. Durante o período experimental foi mantido o fotoperíodo natural e a temperatura média do ambiente, obtida por meio de termômetro de máxima e mínima analógico, diariamente às $16 \mathrm{~h}$, com máxima de 27,7 ${ }^{\circ} \mathrm{C}$ e mínima $18,5{ }^{\circ} \mathrm{C}$. Uma dieta referência (0SCV) foi formulada segundo recomendações de De Blas e Mateos (2010) a fim de atender as exigências nutricionais de coelhos na fase de crescimento. Outras três dietas foram formuladas com a inclusão de 50, 100 e $150 \mathrm{~g} \mathrm{~kg}^{-1}$ de bagaço de cana-de-açúcar enriquecido com vinhaça $(50 \mathrm{SCV}, 100 \mathrm{SCV}$ e $150 \mathrm{SCV}$, respectivamente). As dietas estão expostas na Tabela 3. A formulação se deu com os valores bromatológicos reais do bagaço de cana-de-açúcar enriquecido com vinhaça, além também do valor de ED encontrado no ensaio de digestibilidade. Todas as rações foram peletizadas em grânulos de $12-15 \mathrm{~mm}$ de comprimento por 2-3 mm de diâmetro.

Tabela 3. Ingredientes utilizados por tratamento e composição nutricional das dietas experimentais

\begin{tabular}{|c|c|c|c|c|}
\hline \multirow{2}{*}{ Ingredientes $\left(\mathrm{g} \mathrm{kg}^{-1}\right)$} & \multicolumn{4}{|c|}{ Dietas } \\
\hline & $0 \mathrm{BCV}$ & $50 \mathrm{BCV}$ & $100 \mathrm{BCV}$ & $150 \mathrm{BCV}$ \\
\hline Feno de alfafa & 366,86 & 278,75 & 197,08 & 204,66 \\
\hline Farelo de trigo & 250,00 & 250,00 & 250,00 & 228,50 \\
\hline MDPS & 150,00 & 150,00 & 150,00 & 90,90 \\
\hline Farelo de soja & 73,29 & 106,44 & 138,39 & 150,00 \\
\hline Bagaço + Vinhaça & 0,00 & 50,00 & 100,00 & 150,00 \\
\hline Milho & 100,00 & 100,00 & 100,00 & 100,00 \\
\hline Óleo de soja & 7,41 & 11,18 & 14,62 & 28,76 \\
\hline Melaço de cana em pó & 20,00 & 20,00 & 20,00 & 20,00 \\
\hline Sal comum & 5,00 & 5,00 & 5,00 & 5,00 \\
\hline Premix $^{1}$ & 5,00 & 5,00 & 5,00 & 5,00 \\
\hline Calcário & 4,87 & 9,36 & 10,00 & 9,53 \\
\hline Fosfato bicálcico & 8,37 & 5,15 & 1,90 & 0,00 \\
\hline Bentonita & 5,00 & 5,00 & 5,00 & 5,00 \\
\hline L-Lisina & 2,11 & 1,66 & 1,21 & 0,93 \\
\hline DL-Metionina & 2,09 & 2,46 & 1,80 & 1,73 \\
\hline \multicolumn{5}{|c|}{ Composição nutricional analisada $\left(\mathrm{g} \mathrm{kg}^{-1} \mathrm{MS}\right)$} \\
\hline Matéria seca & 902,2 & 894,7 & 895,2 & 891,7 \\
\hline Matéria mineral & 84,1 & 79,8 & 76,2 & 74,9 \\
\hline Proteína bruta & 169,3 & 180,6 & 168,2 & 178,7 \\
\hline Extrato etéreo & 35,6 & 38,3 & 42,8 & 45,2 \\
\hline Fibra em detergente neutro & 333,2 & 335,1 & 328,4 & 359,6 \\
\hline Fibra em detergente ácido & 140,8 & 145,2 & 120,7 & 155,8 \\
\hline Ligninas & 30,3 & 27,7 & 32,8 & 25,7 \\
\hline Hemiceluloses $^{2}$ & 192,4 & 189,9 & 207,7 & 203,8 \\
\hline Celulose $^{3}$ & 110,5 & 117,5 & 87,9 & 130,1 \\
\hline Cálcio & 10,5 & 11,1 & 9,6 & 9,1 \\
\hline Fósforo total & 4,4 & 4,3 & 3,9 & 3,5 \\
\hline Energia bruta $\left(\mathrm{Kcal} \mathrm{kg}^{-1}\right)$ & 3969,79 & 3939,33 & 3821,66 & 4026,69 \\
\hline Energia digestível ${ }^{4}\left(\mathrm{Kcal} \mathrm{kg}^{-1}\right)$ & 2716,81 & 2675,86 & 2704,54 & 2685,69 \\
\hline
\end{tabular}

$0 \mathrm{BCV}$ - dieta referência;

$50 \mathrm{BCV}$ - dieta contendo a inclusão de $50 \mathrm{~g} \mathrm{~kg}^{-1}$ de bagaço de cana-de-aḉcar enriquecido com vinhaça;

$100 \mathrm{BCV}$ - dieta contendo a inclusão de $100 \mathrm{~g} \mathrm{~kg}^{-1}$ de bagaço de cana-de-açúcar enriquecido com vinhaça

$150 \mathrm{BCV}$ - dieta contendo a inclusão de $150 \mathrm{~g} \mathrm{~kg}^{-1}$ de bagaço de cana-de-açúcar enriquecido com vinhaça; MDPS - Milho desintegrado com palha e sabugo;

Bagaço + Vinhaça - bagaço de cana-de-açúcar enriquecido com $20 \%$ (m/m) de vinhaça;

${ }^{1}$ Composicão do Premix por kg do produto: Vit. A, 2000000 UI; Vit. D3, 20000UI; Vit. E, 4000mg; Vit. K3,

722mg; Vit. B1, 400mg; Vit. B2, 1000mg; Vit. B6, 600mg; Vit. B12, 2000mcg; Niacina, 6000mg; Ácido fólico,

$100 \mathrm{mg}$; Ácido pantotênico, 3000mg; Biotina, $21 \mathrm{mg}$; Cloreto de Colina, $100000 \mathrm{mg}$; Selênio, 19mg; Iodo,

140mg; Cobalto, 200mg; Iron, 20000mg; Cobre, 4000mg; Manganês, 4000mg, Zinco, 14000mg;

${ }^{2}$ FDN-FDA;

${ }^{3}$ FDA-Lignina;

${ }^{4}$ Valores estimados pela equação proposta por De Blas (1989): $\mathrm{CDE}=84,77$ - 1,16(FDA). 
O consumo médio diário (CMD) foi medido através da diferença entre a ração fornecida durante o período e as sobras ao final de cada ensaio. O ganho de peso diário (GPD) obtido pela diferença entre os pesos inicial e final. E a conversão alimentar (CA) mensurada dividindo o CMD pelo GPD.

Os efeitos na produção dos diferentes tratamentos foram avaliados sobre o ganho de peso, consumo de ração e conversão alimentar da desmama aos 65 dias de idade. O experimento encerrou no momento em que a média de peso de todos os tratamentos atingiu o valor mínimo exigido pelo mercado para o abate dos animais, ou seja, $2 \mathrm{~kg}$, sendo medido, portanto, em qual momento do crescimento os animais alimentados com as dietas propostas estariam prontos para serem abatidos e comercializados.

\section{Análises laboratoriais}

Dietas e fezes foram analisadas para determinar as concentrações de matéria seca (MS), matéria mineral $(\mathrm{MM})$ e proteína bruta $(\mathrm{PB})$ utilizando o método e procedimentos harmonizados da AOAC (2000), e a análise de matéria orgânica (MO) se deu pela diferença entre MS e MM. O extrato etéreo (EE) foi analisado após hidrólise ácida. As frações fibrosas, isto é, FDN (Fibra em detergente neutro analisados com amilase, temperatura estável e expressados com inclusão das cinzas residuais, sem sulfito de sódio), FDA (Fibra em detergente ácido expressado incluindo as cinzas residuais) e lignina foram analisados de acordo com Maertens (2002), AOAC (2000) e Van Soest et al. (1991), respectivamente, usando o procedimento sequencial e sistema de sacos filtrantes. As hemiceluloses foram obtidas pela diferença entre FDN e FDA e a celulose pela diferença entre FDA e lignina. A energia bruta foi mensurada através de bomba calorimétrica adiabática.

\section{Análises estatísticas}

Os dados dos três experimentos foram analisados como um delineamento experimental inteiramente casualizado em ANOVA, tendo a dieta como efeito fixo. No ensaio de desempenho fora realizada análise de regressão utilizando o pacote estatístico do SAS (1991) sobre as variáveis CMD, GPD e CA em relação à inclusão de bagaço de cana enriquecido com vinhaça. A gaiola com um animal foi a unidade experimental em todos os casos e o valor de alfa utilizado para avaliar a significância entre médias foi de 0,05 .

\section{RESULTADOS E DISCUSSÃO}

\section{Ensaio de digestibilidade}

Houve efeito significativo $(\mathrm{P}<0,05)$ para CMD e excreção média diária $(\mathrm{EXC})$ sobre a inclu- são do bagaço de cana enriquecido ou não com vinhaça (Tabela 4) em relação à dieta REF. Contudo, verificou-se que entre os tratamentos $\mathrm{BC}$ e $\mathrm{BCV}$ não houveram diferenças $(\mathrm{P}>0,05)$ para $\mathrm{CMD}$ e EXC, demonstrando que a inclusão da vinhaça sobre o bagaço de cana não é responsável pelas alterações sobre o consumo ou excreção. Foram observadas diferenças significativas $(\mathrm{P}<0,05)$ para os coeficientes de digestibilidade da MS, MM, MO, PB, EE e EB, sendo a dieta REF a que apresentou melhores digestibilidades em relação às dietas $\mathrm{BC}$ e $\mathrm{BCV}$, que entre si não apresentaram diferenças $(\mathrm{P}>0,05)$ para as variáveis supracitadas. O coeficiente de digestibilidade da FDN e hemiceluloses foram diferentes $(\mathrm{P}<0,05)$ entre si, enquanto que para o coeficiente de digestibilidade da FDA houve diferença $(\mathrm{P}<0,05)$ somente para o tratamento $\mathrm{BC}$. De posse dos valores de digestibilidade da $\mathrm{PB}$ e EB, além dos níveis de $\mathrm{EB}$ e PB das dietas, foram determinados os valores de $\mathrm{ED}$, proteína digestível $\mathrm{PD}$ e da relação entre Kcal $\mathrm{ED} / \mathrm{g}$ de PD (REL) dos tratamentos estudados (Tabela 2). Valores de REL se apresentaram semelhantes entre os tratamentos, estando os níveis encontrados próximos às recomendações de Machado e Ferreira (2012)

A elevação dos valores de CMD e EXC sobre a inclusão do bagaço de cana se deve ao elevado suprimento e fibra dietética proveniente da inclusão de $28,86 \%$ bagaço de cana no tratamento $\mathrm{BC}$ e $27,18 \%$ BVC sobre a dieta REF. Como consequência deste fato houve uma diluição da energia da dieta, a qual acarretou no aumento do consumo alimentar visando reestabelecer a ingestão energética necessária (GIDENNE; BELLIER, 2000). De Blas e Mateos (2010) justificam que a regulação do consumo decorrente da qualidade da fibra ingerida está relacionada a maior lignificação da parede celular, estimulando o aumento da motilidade ceco-cólica dos coelhos, reduzindo o tempo de retenção cecal e estimulando o consumo mais frequente de alimento.

$O$ coeficiente de digestibilidade do EE encontrado pode estar relacionado com o aumento da motilidade intestinal dos animais alimentados com as dietas $\mathrm{BC}$ e BCV, pois de acordo com Arruda et al. (2002) a maior velocidade do trânsito intestinal pode contribuir para a piora da digestibilidade do extrato etéreo, já que esta se processa mais lentamente em relação a outros nutrientes.

Os coeficientes de digestibilidade da FDN e FDA podem ser melhorados com a elevação dos níveis de amido dietético devido ao aporte adequado de energia suplementar fornecido por um substrato mais equilibrado que melhora a degradabilidade da fração fibrosa ao aumentar a atividade fermentativa. Gidenne et al. (2010) justificam que a digestibilidade da fibra geralmente não é afetada pela concentração da fibra dietética, cuja quantidade de fibra que entra no ceco não é um fator limitante para o processo de fermentação, como o tempo de retenção da digesta no ceco é relativamente curto, permitindo que ocorra 
predominantemente a degradação das frações mais facilmente digeríveis da fibra como pectinas e hemiceluloses.

Baseando-se nos valores obtidos pode-se observar que a inclusão de vinhaça elevou os valores de
ED e PD do bagaço de cana. A provável explicação pode estar na presença de leveduras na vinhaça que são digeridas pelo trato gastrointestinal e fornecem quantidade extra de proteína e energia que será consequentemente aproveitada pelo animal.

Tabela 4. Consumo médio diário (CMD), Excreção média diária (EXC) e coeficientes de digestibilidade dos princípios nutritivos das dietas experimentais mensurados em coelhos aos 55 dias de idade

\begin{tabular}{|c|c|c|c|c|}
\hline & REF & $\mathrm{BC}$ & $\mathrm{BCV}$ & $\mathrm{CV}$ \\
\hline CMD, $\mathrm{g}$ & $79,70 \mathrm{~b}$ & $138,28 \mathrm{a}$ & $147,61 \mathrm{a}$ & 16,34 \\
\hline $\mathrm{EXC}, \mathrm{g}$ & $26,47 \mathrm{~b}$ & 67,46 a & $69,93 \mathrm{a}$ & 17,10 \\
\hline Matéria seca, $\%$ & $67,41 \mathrm{a}$ & $51,04 \mathrm{~b}$ & $52,65 \mathrm{~b}$ & 5,91 \\
\hline Matéria mineral, \% & $69,13 \mathrm{a}$ & $60,73 \mathrm{~b}$ & $55,12 \mathrm{~b}$ & 11,31 \\
\hline Matéria orgânica, \% & $67,26 \mathrm{a}$ & $50,25 \mathrm{~b}$ & $52,47 \mathrm{~b}$ & 5,94 \\
\hline Proteína bruta, $\%$ & $78,75 \mathrm{a}$ & $74,39 \mathrm{~b}$ & $73,93 \mathrm{~b}$ & 5,07 \\
\hline Extrato etéreo, \% & $85,64 \mathrm{a}$ & $72,54 \mathrm{~b}$ & $78,38 \mathrm{~b}$ & 12,36 \\
\hline Fibra em detergente neutro, $\%$ & $40,32 \mathrm{a}$ & $23,32 \mathrm{c}$ & $32,82 \mathrm{~b}$ & 16,33 \\
\hline Fibra em detergente ácido, \% & $29,12 \mathrm{a}$ & $5,06 \mathrm{~b}$ & $24,56 \mathrm{a}$ & 31,32 \\
\hline Hemiceluloses, \% & 52,46 a & $39,69 \mathrm{c}$ & $45,46 \mathrm{~b}$ & 11,19 \\
\hline Energia bruta, \% & $67,51 \mathrm{a}$ & $50,92 \mathrm{~b}$ & $52,58 \mathrm{~b}$ & 6,04 \\
\hline
\end{tabular}

Médias seguidas com letras diferentes na mesma linha diferem $(\mathrm{P}<0,05)$ pelo teste de Duncan;

REF - dieta referência;

$\mathrm{BC}$ - dieta referência substituída em $300 \mathrm{~g} \mathrm{~kg}^{-1}$ por bagaço de cana-de-açúcar;

$\mathrm{BCV}$ - dieta referência substituída em $300 \mathrm{~g} \mathrm{~kg}^{-1}$ por bagaço de cana-de-açúcar enriquecido com vinhaça;

CV - coeficiente de variação.

\section{Ensaio de cecotrofia}

A composição química dos cecotrofos, de acordo com as dietas experimentais, está exposta na Tabela 5. A MS dos cecotrofos foi alterada $(\mathrm{P}<0,05)$ pela inclusão do bagaço de cana-de-açúcar na dieta, apresentando-se maior na dieta REF. Por outro lado, não houveram alterações $(\mathrm{P}>0,05)$ no teor de $\mathrm{PB}$ destes cecotrofos. A inclusão de vinhaça alterou $(\mathrm{P}<0,05)$ a quantidade de $\mathrm{MM}$ encontrado nos cecotrofos, reduzindo os níveis deste quando presente no bagaço de cana. O contrário ocorre com a MO.

Não houve a influência $(\mathrm{P}>0,05)$ do peso vivo na determinação das diferenças. Pode-se averiguar que houve aumento significativo $(\mathrm{P}<0,05)$ no consumo de MS dos animais submetidos às dietas contendo bagaço de cana, contudo o acréscimo de vinhaça não interferiu $(\mathrm{P}>0,05)$ no consumo entre os tratamentos $\mathrm{BC}$ e $\mathrm{BCV}$. A produção média de cecotrofos foi menor nos tratamentos $\mathrm{BC}$ e $\mathrm{BCV}(\mathrm{P}<0,05)$ e o consumo de ração maior $(\mathrm{P}<0,05)$ para estes tratamentos.
A inclusão de bagaço de cana enriquecido ou não com vinhaça não alterou $(\mathrm{P}>0,05)$ o conteúdo proteico dos cecotrofos, contudo em função do maior consumo de ração houve um consequente aumento $(\mathrm{P}<0,05)$ no consumo de proteína bruta nos tratamentos $\mathrm{BC}$ e BCV. Como resultado foi verificado redução $(\mathrm{P}<0,05)$ na contribuição nutritiva em matéria seca (CNMS), a partir da inclusão dos alimentos teste. Esta inclusão não afetou $(\mathrm{P}>0,05)$ a contribuição nutritiva em proteína bruta (CNPB).

A produção média de cecotrofos, aos 63 dias de idade, gira em torno de $25 \mathrm{~g} \mathrm{MS}$ dia $^{-1}$ (GIDENNE; LEBAS, 1984). Os valores sugeridos pelos autores são bem próximos aos encontrados neste trabalho.

A cecotrofia pode ser influenciada por diversos fatores e dentre eles está a composição das dietas, sobretudo no que diz respeito à fração fibrosa. Em dietas com baixo teor de fibra a cecotrofia é reduzida em função da baixa motilidade intestinal e maior tempo de retenção cecal. Gomes e Ferreira (1999), avaliando a composição química dos cecotro- 
fos de coelhos diferentes dietas, encontrou valores de MS significativamente maiores $(\mathrm{p}<0,05)$ para dietas contendo palha seca de milho branco $(27,44 \%)$ e feno de coast-cross $(27,54 \%)$, quando comparado a dietas contendo feno de alfafa $(25,08 \%)$, feno de guandú $(26,69 \%)$ e palha de feijão $(26,39 \%)$. Todos os valores se apresentaram maiores quando compara- dos com os tratamentos $\mathrm{BC}$ e BCV. Por outro lado, o valor de $\mathrm{PB}$ dos cecotrofos do presente experimento foi semelhante nos tratamentos contendo palha seca de milho branco $(25,30 \%)$ e feno de coast-cross $(25,34 \%)$, enquanto que os tratamentos contendo feno de alfafa $(29,66 \%)$, feno de guandú $(26,78 \%)$ e palha de feijão $(28,40 \%)$ foram superiores.

Tabela 5. Composição química dos cecotrofos e sua contribuição nutritiva de acordo com as dietas experimentais

\begin{tabular}{|c|c|c|c|c|}
\hline Composição dos cecotrofos $\left(\mathrm{g} \mathrm{kg}^{-1}\right)$ & $\mathrm{REF}$ & $\mathrm{BC}$ & $\mathrm{BCV}$ & CV (\%) \\
\hline Matéria seca & $261,7 \mathrm{a}$ & $219,3 \mathrm{~b}$ & $222,7 \mathrm{~b}$ & 5,65 \\
\hline Proteína bruta & 236,8 & 246,5 & 254,3 & 9,14 \\
\hline Matéria orgânica & $906,0 \mathrm{a}$ & $899,0 \mathrm{~b}$ & $905,2 \mathrm{a}$ & 0,50 \\
\hline Matéria mineral & $94,0 \mathrm{a}$ & $92,5 \mathrm{a}$ & $87,4 \mathrm{~b}$ & 4,75 \\
\hline \multicolumn{5}{|l|}{ Contribuição nutritiva } \\
\hline Peso vivo médio, $g$ & 1937,90 & 2166,41 & 2170,76 & 13,08 \\
\hline Produção de cecotrofos, g MS/dia & 26,17 a & $21,93 \mathrm{~b}$ & $22,27 \mathrm{~b}$ & 5,65 \\
\hline Consumo médio, g MS/dia & $78,77 \mathrm{~b}$ & $146,63 \mathrm{a}$ & $135,61 \mathrm{a}$ & 23,90 \\
\hline Conteúdo de proteína bruta, $\%$ & 25,30 & 26,93 & 27,57 & 9,29 \\
\hline Consumo de proteína, $\mathrm{g} / \mathrm{d}$ & $13,97 \mathrm{~b}$ & $20,75 \mathrm{a}$ & $20,28 \mathrm{a}$ & 25,07 \\
\hline CNMS, $\%$ & $17,25 \mathrm{a}$ & $13,82 \mathrm{~b}$ & $13,34 \mathrm{~b}$ & 19,33 \\
\hline $\mathrm{CNPB}, \%$ & 22,83 & 23,31 & 22,06 & 19,05 \\
\hline
\end{tabular}

Médias seguidas com letras distintas na mesma linha diferem $(\mathrm{P}<0,05)$ pelo teste de Tukey;

REF - dieta referência;

$\mathrm{BC}$ - dieta referência substituída em $300 \mathrm{~g} \mathrm{~kg}^{-1}$ por bagaço de cana-de-açúcar;

$\mathrm{BCV}$ - dieta referência substituída em $300 \mathrm{~g} \mathrm{~kg}^{-1}$ por bagaço de cana-de-açúcar enriquecido com vinhaça;

$\mathrm{CV}$ - coeficiente de variação;

CNMS - contribuição nutritiva em matéria seca;

CNPB - contribuição nutritiva em proteína bruta.

Vieira et al. (2003) encontraram maiores taxas de renovação dos constituintes cecais dos animais alimentados com estas dietas contendo maior conteúdo fibroso, reduzindo o tempo de retenção cecal e elevando os valores de produção de cecotrofos. Esse fato vai de encontro com o obtido no recente estudo, de modo que a maior produção de cecotrofos obteve também a melhor CNMS. Contudo, podese observar que a CNPB não seguiu o mesmo padrão e a explicação para esta ocorrência diz respeito ao menor valor de MS e maior valor de proteína bruta consumida pelos animais do tratamento $\mathrm{BC}$ e $\mathrm{BCV}$, permitindo que a CNPB apresentasse valor semelhante $(\mathrm{P}>0,05)$ ao do tratamento REF.

\section{Ensaio de desempenho}

A inclusão do bagaço de cana enriquecido com vinhaça não interferiu $(\mathrm{P}>0,05)$ sobre o peso vivo e GPD dos animais (Tabela 6). Contudo, obser- vou-se diferenças $(\mathrm{P}<0,05)$ para as variáveis $\mathrm{CMD}$ e $\mathrm{CA}(\mathrm{P}<0,05)$.

A análise de regressão sobre os dados revelou que o modelo quadrático foi o que melhor se adequou para a predição dos fenômenos ocorridos. Derivando-se a equação quadrática para GPD do período total foi encontrado o valor ótimo para esta variável igual a 5,19\% de inclusão do bagaço de cana-deaçúcar enriquecido com vinhaça na dieta para coelhos em crescimento.

Faria et al. (2008) encontraram piora no desempenho de coelhos alimentados com dietas simplificadas a base de feno da rama de mandioca. Seus dados demonstram valores de peso vivo aos 70 dias $(1884,0 \mathrm{~g})$, GPD $(35,0 \mathrm{~g}), \mathrm{CMD}(159,0 \mathrm{~g})$ e CA $(4,6)$ inferiores aos encontrados no presente estudo. Contudo, ao avaliarem dietas simplificadas a base de feno de alfafa os autores ora citados encontraram valores de peso vivo aos 70 dias e GPD semelhantes aos encontrados no ensaio atual $(1958,0$ g e $37 \mathrm{~g}$, respectivamente). 
F. N. A. FERREIRA et al.

Tabela 6. Peso vivo aos 30 dias, peso vivo aos 65 dias, ganho de peso diário (GPD), consumo médio diário (CMD) e conversão alimentar (CA) de coelhos alimentados com níveis crescentes de bagaço de cana-de-açúcar enriquecido com vinhaça

\begin{tabular}{|c|c|c|c|c|c|}
\hline & \multicolumn{4}{|c|}{ Dietas } & \multirow{2}{*}{$\mathrm{CV}(\%)$} \\
\hline & 0BCV & $50 \mathrm{BCV}$ & 100BCV & $150 \mathrm{BCV}$ & \\
\hline Mortalidade, $n^{\circ}$ & 2 & 2 & 2 & 2 & - \\
\hline Peso aos 30 dias, $\mathrm{g}$ & 728,50 & 730,50 & 730,00 & 738,75 & - \\
\hline Peso aos 65 dias, $g$ & 2061,81 & 2118,87 & 2074,36 & 2000,97 & 10,47 \\
\hline $\mathrm{GPD}^{1}, \mathrm{~g} / \mathrm{dia}$ & 38,09 & 39,67 & 38,41 & 36,06 & 12,21 \\
\hline $\mathrm{CMD}^{2}, \mathrm{~g} / \mathrm{dia}$ & $112,95 \mathrm{~b}$ & $115,84 \mathrm{ab}$ & $123,83 a b$ & $126,56 \mathrm{a}$ & 11,06 \\
\hline $\mathrm{CA}^{3}, \mathrm{~g} / \mathrm{g}$ & $2,97 \mathrm{bc}$ & $2,93 \mathrm{c}$ & $3,28 \mathrm{ab}$ & $3,53 \mathrm{a}$ & 9,35 \\
\hline
\end{tabular}

Médias seguidas com letras distintas na mesma linha diferem $(\mathrm{P}<0,05)$ pelo teste de Tukey;

$0 \mathrm{BCV}$ - dieta referência;

$50 \mathrm{BCV}$ - dieta contendo a inclusão de $50 \mathrm{~g} \mathrm{~kg}^{-1}$ de bagaço de cana-de-açúcar enriquecido com vinhaça;

100BCV - dieta contendo a inclusão de $100 \mathrm{~g} \mathrm{~kg}^{-1}$ de bagaço de cana-de-açúcar enriquecido com vinhaça;

$150 \mathrm{BCV}$ - dieta contendo a inclusão de $150 \mathrm{~g} \mathrm{~kg}^{-1}$ de bagaço de cana-de-açúcar enriquecido com vinhaça;

$\mathrm{CV}$ - coeficiente de variação;

${ }^{1} \mathrm{Y}=-0,039185 \mathrm{X}^{2}+0,440745 \mathrm{X}+38,182225\left(\mathrm{R}^{2}=97,73\right)$;

${ }^{2} \mathrm{Y}=-0,0016 \mathrm{X}^{2}+1,00042 \mathrm{X}+112,43435\left(\mathrm{R}^{2}=95,70\right)$

${ }^{3} \mathrm{Y}=0,003028 \mathrm{X}^{2}-0,004805 \mathrm{X}+2,948165\left(\mathrm{R}^{2}=94,92\right)$.

Contrastam também aos valores do presente ensaio, dados de Trocino et al. (2010), que ao avaliar a inclusão de diferentes níveis de fibra solúvel e fontes proteicas encontrou média de peso vivo de 2050,4 g para animais com 55 dias e 3021,4 g aos 76 dias. Os referidos autores encontraram ainda médias de 50,56 g para GPD no período total (35 a 76 dias).

Verifica-se que o efeito do incremento do consumo como resultado da maior inclusão do bagaço de cana enriquecido com vinhaça é explicado por Dehalle (1981) ao afirmar que o coelho é capaz de manter o seu desempenho, desde que consuma dietas com no mínimo $2260 \mathrm{Kcal} \mathrm{kg}^{-1} \mathrm{MS}$, apenas ajustando o consumo alimentar, de modo que o animal torne-se incapaz de elevar o consumo a ponto de reajustar a ingestão energética em dietas com níveis inferiores ao apresentado.

Oliveira et al. (2013), avaliando a inclusão de $0,25,50,75$ e $100 \mathrm{~g} \mathrm{~kg}^{-1}$ vinhaça líquida em dietas comerciais sobre o desempenho de coelhos em crescimento dos 30 aos 77 dias, verificaram melhores resultados segundo análise de regressão, quando a vinhaça foi incluída em $87,9 \mathrm{~g} \mathrm{~kg}^{-1}$, superior às inclusões trabalhadas no presente estudo, que foram 10 , 20 e $30 \mathrm{~g} \mathrm{~kg}^{-1}$ de vinhaça líquida sobre o peso de ração para os tratamentos 5, 10 e $15 \%$, respectivamente. De semelhante modo, Maertens et al. (1994) afirmaram que a inclusão de $4 \%$ de vinhaça líquida em dietas para coelhos em crescimento não interfere no desempenho dos animais.

\section{CONCLUSÕES}

Os resultados demonstraram que a utilização do bagaço de cana-de-açúcar enriquecido com vinhaça em dietas para coelhos em crescimento se mostrou viável, de modo que a inclusão não alterou o ganho de peso diário dos animais e, portanto, o tempo necessário para atingir o peso de abate. A inclusão de vinhaça promove a melhoria dos valores de energia digestível e proteína digestível do bagaço de cana-de-açúcar in natura.

\section{AGRADECIMENTOS}

À CAPES, CNPq e FAPEMIG pelos recursos disponibilizados para a realização dos experimentos.

\section{REFERÊNCIAS}

AOAC, Official Methods of Analysis, 17th ed. Association of Official Analytical Chemists, Arlington, VA, 2000.

ARRUDA, A. M. V. et al. Digestibilidade aparente dos nutrientes de rações contendo diferentes fontes de fibra e níveis de amido com coelhos em crescimento. Revista Brasileira de Zootecnia, Viçosa, v. 31, n. 3, p. 1166-1175, 2002.

CARABAÑO, R. M.; FRAGA, M. J.; DE BLAS, J. 
C. Effect of protein source in fibrous diets on performance and digestive parameters of fattening rabbits. Journal of Applied Rabbit Research, Oregon, v. 12, n. 3, p. 201-204, 1989.

COELHO, C. C. G. M. Utilização digestiva de dietas semi-simplificadas com fenos enriquecidos com vinhaça para coelhos em crescimento. 2010. 66 f. Dissertação (Mestrado em Zootecnia: Área de Concentração em Nutrição Animal) - Universidade Federal de Minas Gerais, Belo Horizonte, 2010.

DE BLAS, C. Alimentación del conejo. Madrid: Ed. Mundi-Prensa, 1989. 175 p.

DE BLAS, C.; MATEOS, G. G. Feed formulation. In: DE BLAS, C.; WISEMAN, J. (Ed.). Nutrition of the rabbit. Cambridge: CABI International, 2010. v. 2, cap. 12, p. 222-232.

DEHALLE, C. Equilibre entre les apports azotés et énergétiques dans l'alimentation du Çapin en croissance. Annales de Zootechnie, Paris, v. 30, n. 2, p. 197-208, 1981.

FARIA H. G. et al. Efeito da utilização de dietas simplificadas, à base de forragem, sobre a digestibilidade e o desempenho de coelhos Nova Zelândia. Revista Brasileira de Zootecnia, Viçosa, v. 37, n. 10, p. 1797-1801, 2008.

GIDENNE, T.; BELLIER, R. Use of digestible fibre in replacement to available carbohydrates: Effect on digestion, rate of passage and caecal fermentation pattern during the growth of the rabbit. Livestock Production Science, Foulum, v. 63, n. 2, p.141-152, 2000.

GIDENNE, T. et al. Fibre digestion. In: DE BLAS, C.; WISEMAN, J. (Ed.). The Nutrition of the Rabbit. Cambridge: CABI International, 2010. v. 2, cap. 5 , p. $66-82$.

GIDENNE, T.; LEBAS, F. Evolution circadienne du contenu digestif chez le lapin en croissance: Relation avec la caecotrophie. In: WORLD RABBIT CONGRESS, 3., 1984, Roma. Proceedings... Roma: INRA, 1984. p. 494-501.

GOMES, A. V. C.; FERREIRA, W. M. Composição química e contribuição nutritiva de cecotrofos de diferentes dietas. Revista Brasileira de Zootecnia, Viçosa, v. 28, n. 6, p. 1297-1301, 1999.

HIDALGO, K. et al. Utilización de la vinaza de destilería como aditivo para pollos en ceba. Revista Cubana de Ciencia Agrícola, San José de las Lajas, v. 43, n. 3, p. 281-284, 2009.

MACHADO, L. C.; FERREIRA, W. M. Atualidades em nutrição de coelhos: 2006 a 2011. Revista Brasileira de Cunicultura, Bambuí, v. 1, n. 1, p. 17-27, 2012 .

MAERTENS, L.; DUCATELLE, R.; DE GROOTE, G. Influence de l'incorporation alimentaire d'une vinasse a taux élevé de parois cellulaires de levure sur les performances du lapin en engraissement. World Rabbit Science, Valência, v. 2, n. 1, p. 1519, 1994.

MAERTENS, L. et al. Nutritive value of raw materials for rabbits: EGRAN Tables 2002. World Rabbit Science, Valência, v. 10, n. 4, p. 157-166, 2002.

MONTEILS, V. et al. Potential core species and satellite species in the bacterial community within the rabbit Caecum. Microbiology Ecology, Delft, v. 66, n. 3, p. 620-629, 2008.

OLIVEIRA, M. C. et al. Effect of including liquid vinasse in the diet of rabbits on growth performance. Revista Brasileira de Zootecnia, Viçosa, v. 42, n. 4, p. 259-263, 2013.

PÉREZ, J. M. et al. European reference method for in vivo determination of diet digestibility in rabbits. World Rabbit Science, Valência, v. 3, n.1, p. 41-43, 1995.

SAS Statistical Analysis System Institute Inc. User's Guide, Statistics, Version 6.03. Edition SAS Institute Inc., Cary, NC. 1991.

SCHNEIDER, B. A.; FLATT, W. P. The evaluation of feeds through digestibility experiences. Athens: The University of Georgia, 1975. 423 p.

STRAPASSON, A. Etanol y medio ambiente. In: CONGRESO INTERNACIONAL SOBRE AZÚCAR Y DERIVADOS DE LA CAÑA, 9., 2006, Havana. Memorias... Havana: ICIDCA, 2006. p. 51-63.

TROCINO, A. et al. Effect of dietary soluble fibre level and protein source on growth, digestion, caecal activity and health of fattening rabbits. World Rabbit Science, Valência, v. 18, n. 4, p. 199-210, 2010.

VAN SOEST, P. J.; ROBERTSON, J. B.; LEWIS, B. A. Methods for dietary fiber, neutral detergent fiber, and nonstarch polysaccharides in relation to animal nutrition. Journal of Dairy Science, Champaign, v. 74, n., p. 3583-3597, 1991.

VIEIRA, F. S.; GOMES, A. V. C.; PESSOA, M. F. Efeito da granulometria do bagaço de cana sobre as características digestivas e a contribuição nutritiva dos cecotrofos. Revista Brasileira de Zootecnia, Viçosa, v. 32, n. 4, p. 935-941, 2003. 
VILLAMIDE, M. J. Methods of energy evaluation of feed ingredients for rabbits and their accuracy. Animal Feed Science Technology, Madrid, v. 57, n. 4, p. 211-223, 1995.

VILLAMIDE, M. J. et al. Protein digestion. In: DE BLAS,C.; WISEMAN, J. (Ed.). Nutrition of the rabbit. Cambridge: CABI International, 2010. v. 2, cap. 3 , p. 39-55.

ZANATO, J. A. F. Bagaço de cana-de-açúcar hidrolisado para coelhos em crescimento. 2008. $78 \mathrm{f}$. Dissertação (Mestrado em Zootecnia: Área de Concentração em Produção Animal) - Universidade Estadual Paulista, Jaboticabal, 2008. 